\title{
Progestogen-induced alterations and their ecological relevance in different embryonic and adult behaviours of an invertebrate model species, the great pond snail (Lymnaea stagnalis)
}

\author{
Reka Svigruha $^{1,2} \cdot$ Istvan Fodor ${ }^{2} \cdot$ Judit Padisak $^{1} \cdot$ Zsolt Pirger $^{2}$ (D) \\ Received: 6 May 2020 / Accepted: 14 December 2020 / Published online: 21 December 2020 \\ (C) The Author(s) 2020
}

\begin{abstract}
The presence of oral contraceptives (basically applying estrogens and/or progestogens) poses a challenge to animals living in aquatic ecosystems and reflects a rapidly growing concern worldwide. However, there is still a lack in knowledge about the behavioural effects induced by progestogens on the non-target species including molluscs. In the present study, environmental progestogen concentrations were summarised. Knowing this data, we exposed a well-established invertebrate model species, the great pond snail (Lymnaea stagnalis) to relevant equi-concentrations $\left(1,10,100\right.$, and $500 \mathrm{ng} \mathrm{L^{-1 }}$ ) of mixtures of four progestogens (progesterone, drospirenone, gestodene, levonorgestrel) for 21 days. Significant alterations were observed in the embryonic development time, heart rate, feeding, and gliding activities of the embryos as well as in the feeding and locomotion activity of the adult specimens. All of the mixtures accelerated the embryonic development time and the gliding activity. Furthermore, the 10,100 , and $500 \mathrm{ng} \mathrm{L}^{-1}$ mixtures increased the heart rate and feeding activity of the embryos. The 10,100 , and $500 \mathrm{ng} \mathrm{L}^{-1}$ mixtures affected the feeding activity as well as the 1,10 , and $100 \mathrm{ng} \mathrm{L}^{-1}$ mixtures influenced the locomotion of the adult specimens. The differences of these adult behaviours showed a biphasic response to the progestogen exposure; however, they changed approximately in the opposite way. In case of feeding activity, this dose-response phenomenon can be identified as a hormesis response. Based on the authors' best knowledge, this is the first study to investigate the non-reproductive effects of progestogens occurring also in the environment on molluscan species. Our findings contribute to the global understanding of the effects of human progestogens, as these potential disruptors can influence the behavioural activities of non-target aquatic species. Future research should aim to understand the potential mechanisms (e.g., receptors, signal pathways) of progestogens induced behavioural alterations.
\end{abstract}

Keywords Progestogen exposure $\cdot$ Lymnaea stagnalis $\cdot$ Developmental changes $\cdot$ Heartbeat $\cdot$ Locomotion $\cdot$ Feeding activity

\section{Introduction}

In the last few years, it has become clear that pharmacologically active compounds (PhACs), as emerging pollutants in

Responsible Editor: Philippe Garrigues

Zsolt Pirger

pirger.zsolt@okologia.mta.hu

1 Department of Limnology, University of Pannonia, Veszprém 8200, Hungary

2 NAP Adaptive Neuroethology Research Group, Department of Experimental Zoology, Balaton Limnological Institute, Centre for Ecological Research, Tihany 8237, Hungary aquatic ecosystems, pose a challenge to animals and has initiated a rapidly growing concern on their environmental impact (Can et al. 2014; Liu et al. 2011a; Maasz et al. 2019; Postigo et al. 2010). One such group of PhACs are the synthetic oral contraceptives (basically applying estrogens and/or progestogens). For a long time, the estrogens were the most extensively studied contraceptive compounds; their effects have been shown on different invertebrate and vertebrate aquatic species (Bhandari et al. 2015; Caldwell et al. 2008; Costa et al. 2010; Huang et al. 2015; Hutchinson 2002; Islam et al. 2020; Kashian and Dodson 2004; Ketata et al. 2008; Matthiessen and Sumpter 1998; Torres et al. 2015; Zou and Fingerman 1997). Recently, another class of contraceptive pharmaceuticals has emerged into the focus in ecotoxicology: 
the progesterone (PRG) and its synthetic analogue progestins (e.g. drospirenone [DRO], gestodene [GES], and levonorgestrel [LNG]); generally referred to as progestogens (SitrukWare and Nath 2010). In previous studies, PRO, DRO, GES, and LNG were detected at concentrations of typically a few ng L ${ }^{-1}$ in surface waters (Chang et al. 2011; Fent 2015; Liu et al. 2011a, b; Orlando and Ellestad 2014; Shen et al. 2018; Vulliet et al. 2008; Yost et al. 2014). In our pilot study area, by analysing freshwater samples from the catchment area of the largest shallow lake in Central Europe, Lake Balaton, varying progestogen concentrations of $0.6-50 \mathrm{ng} \mathrm{L}^{-1}$ were detected (Avar et al. 2016; Maasz et al. 2019). Despite these relatively low environmental concentrations, progestogens have extreme stability against oxidation or degradation in the environment due to the polycyclic sterane frame and ethynyl-group (LNG, GES). Therefore, the continuous and simultaneous presence of these chemicals might be enough to impose a possible effect on non-target aquatic biota (Frankel et al. 2016; Giusti et al. 2014; Maasz et al. 2017; Tillmann et al. 2001; Zrinyi et al. 2017). To note, the large majoritIn the last few yearsy of these studies applies only a single $\mathrm{PhAC}$ in the laboratory experiments; however, there is a lack of information about the adverse mixture effects of progestogens, especially at average environmental $(\sim 1-10$ ng L ${ }^{-1}$ ) concentrations.

Molluscs, which is the second most diverse animal group, are generally considered as excellent (bio)indicators (e.g. sensitive, easy to collect, and ubiquitous) of ecosystem health and frequently used for environmental studies. One such species is the great pond snail (Lymnaea stagnalis) that was found to be a sensitive and suitable species in ecotoxicological context. Several toxicological values and endpoints are available for L. stagnalis such as quantified reproductive, growth parameters, behavioural patterns as well as cellular and molecular biomarkers and/or responses (Amorim et al. 2019). The relevance of $L$. stagnalis in ecotoxicological studies is also supported historically: it became the first recognised, aquatic, non-arthropod invertebrate model organism in environmental risk assessments (Amorim et al. 2019; Ducrot et al. 2014; Giusti et al. 2014; Fodor et al. 2020a; Pirger et al. 2018). The developed standard reproduction and neurotoxicity tests of human drugs were officially approved by the national coordinators of the Organization for Economic Cooperation and Development (OECD 2016).

In our previous study, by investigating the effect of progestogens on the reproduction of $L$. stagnalis, we observed that parental progestogen exposure could cause alterations in the egg production of adult specimens as well as molecular and cellular changes in the early phase of embryonic development (Zrinyi et al. 2017). Here, our aim was to extend these pilot observations in an overarching investigation by monitoring different embryonic and adult behavioural parameters and possible underlying mechanisms at the cellular level. Such additional information could allow integrating findings into a complete picture of the mode of action of progestogens and pave the way for understanding the ecotoxic effects in more detail. To do so, embryos and adult specimens were exposed to different equi-concentrations $(1,10,100,500 \mathrm{ng}$ $\mathrm{L}^{-1}$ ) of mixtures of four progestogens (PRG, DRO, GES, and LNG). Significant alterations in embryonic development time, heartbeat, feeding, and gliding activities and in adult feeding and locomotion activities were observed. Also, significant changes were determined in stress markers such as protein deglycase DJ-1 and p38alpha mitogen-activated protein kinase of the central nervous system (CNS).

\section{Materials and methods}

\section{Chemicals}

HPLC grade PRG (CAS No.: 57-83-0), LNG (CAS No.: 79763-7), GES (CAS No.: 60282-87-3), and DRO (CAS No.: 67392-87-4) were used for the treatments as progestogen agents (Sigma-Aldrich, Hungary). Stock solutions of them $\left(1 \mathrm{mg} \mathrm{mL}{ }^{-1}\right)$ were prepared in acetone (ACS reagent, $\geq$ 99.5\%; CAS No.: 67-64-1; VWR, Hungary). From these stock solutions, $1 \mu \mathrm{g} \mathrm{mL}^{-1}$ working solutions were prepared (solvent at $\leq 0.01 \%$ ). This working was added into the artificial snail water of experimental plastic well plates (embryos) or glass tanks (adults) with appropriate aliquots to reach the desired nominal equi-concentrations of $1,10,100$, and $500 \mathrm{ng}$ $\mathrm{L}^{-1}$ (mixtures of progestogens).

\section{Experimental animals and progestogen exposure}

Adult (3-4 months old) specimens of $L$. stagnalis, originating from our laboratory-bred stocks (Balaton Limnological Institute, Tihany, Hungary), were randomly selected for use in our experiments. Snails were kept in large (20 L) holding tanks containing oxygenated low-copper artificial snail water at a constant temperature of $20^{\circ} \mathrm{C}\left( \pm 1.5^{\circ} \mathrm{C}\right)$ and on light:dark regime of $12 \mathrm{~h}: 12 \mathrm{~h}$. Specimens were fed on lettuce ad libitum three times a week and on vegetable-based fish food (TETRA Werke Company, Germany) one time a week. All procedures on snails were performed according to the protocols approved by the Scientific Committee of Animal Experimentation of the Balaton Limnological Institute (VE-I-001/01890-10/2013). Efforts were made to minimise the number of animals used in the experiments.

Adult snails were food-deprived for 2 days before the behavioural experiments. The experiments consisted of control and treated groups (12 adult animals/group/tank; $n=60$ total number of adult animals per replicates) and data were obtained from 3 independent treatment series. Adult animals in the treated groups were exposed to $1,10,100$, and $500 \mathrm{ng} \mathrm{L}^{-1}$ of 
mixtures of progestogens in $2 \mathrm{~L}$ artificial snail water for 3 weeks, respectively. Animals in the control group were kept in $2 \mathrm{~L}$ artificial snail water originally containing the solvent $(\leq$ $0.000001 \%$ ). Any physiological changes induced by the solvent cannot be observed. Based on our previous study (Zrinyi et al. 2017), water was totally refreshed weekly, and progestogens were added to reach the desired nominal concentrations again. During the 21-day exposure, highly paying attention to the same amount in the groups, specimens were fed on lettuce three times a week.

Egg masses were collected from the large tank of laboratory populations within $6 \mathrm{~h}$ after egg laying (cleavage period). Following previous studies (Filla et al. 2009; Voronezhskaya et al. 1999), we used isolated living embryos to ensure the appropriate tracking of behaviours and more standardised and reproducible experiments. Individual embryos were separated randomly from freshly laid egg masses and placed into 6-well plates (BioLite 6 Well Multidish; \#100184 Thermo Fischer Scientific) with the following arrangement: $n=10$ embryos/group/well in $10 \mathrm{~mL}$ oxygenated low-copper artificial snail water or progestogen-containing solutions. The experiments consisted of control and treated groups and data were obtained from 3 independent treatment series. Embryos in the control experiments were kept in $10 \mathrm{~mL}$ artificial snail water originally containing the solvent $(\leq 0.0001 \%)$. No effects of the solvent were observed. Embryos in the treated groups were exposed to $1,10,100$, and $500 \mathrm{ng} \mathrm{L}^{-1}$ of mixtures of PRG, LNG, GES, and DRO from cleavage period (E0 stage) to embryo hatching (E100 stage). Water and treated solutions were refreshed every 3 days.

\section{Observation of embryonic development}

The development of L. stagnalis embryos generally takes place approx. 11-12 days in transparent eggs packaged in a translucent gelatinous mass, hence can be conveniently monitored by a stereomicroscope. The embryonic development was staged on the basis of a specific set of morphological, morphometric, and behavioural features, according to Morrill (Morrill 1982 ) and Mescheriakov (Mescheriakov 1990). Schematic (basic) representation of the embryogenesis of L. stagnalis modified after Morrill, showing the length of the embryo, and some of the morphological criteria and behavioural features, was used to determine different embryonic stages (see Supplementary Fig. 1). However, the exact time of embryogenesis depends on a number of conditions such as temperature, photoperiod, and ionic-composition of water, at the location where they are being raised. In this respect, the development from first cleavage (E0 stage) to embryos hatching (E100 stage) takes place approx. 14-15 days in our laboratory, similar to others (Marois and Croll 1991). To determine the dynamic of hatching rate of embryos caused by different progestogen exposures, the generalised additive modelling (GAM) (Hastie and Tibshirani 1986) was applied (see Supplementary Fig. 2). Development of the vehicle control and treated embryos was monitored every day until hatching using a Leica M205c stereomicroscope equipped with a DFC3000G (Leica) digital camera. Pictures were taken every day, starting with the cell proliferation, following the changes until the hatching.

\section{Behaviour tests}

\section{In embryos}

Based on the findings of Voronezhskaya and Filla (Filla et al. 2009; Voronezhskaya et al. 1999): heartbeat, gliding by their foot on the inner surface of the egg capsule, and feeding activity (radula protrusion) were monitored from the E65, E85, and E95 stages, respectively, in both control and progestogens-treated groups. Following the abovementioned studies, the heartbeat and the radula protrusion (as fast behaviours) were counted for $2 \mathrm{~min}$, while the number of circles performed by gliding embryos (as a slow behaviour) was monitored for $4 \mathrm{~min}$ by Leica M205c stereomicroscope. To make the results of heartbeat more comparable (to reduce standard deviation), the relative numbers were used in the case of all groups from 3 independent series.

\section{In adults}

Locomotion test-Snails from vehicle control and progestogen-treated groups were individually placed in an experimental tank $(10 \times 20 \times 3 \mathrm{~cm}$, (Salanki et al. 2003) $)$ on the 21 st day of the treatments. After acclimatisation for $10 \mathrm{~min}$, the locomotion route of snails was marked continuously by a marker for $4 \mathrm{~min}$. Digital photographs of each animal were taken by Nikon D5100 camera after the test. Based on individual pictures, the traces made by a single animal were measured (in $\mathrm{cm}$ ) and analysed using the Mousotron8.2 freeware software (BlackSun, www.techspot.com/download).

Feeding test-Feeding behaviour was followed by placing the snails individually into a Petri dish filled with $20 \%$ sucrose solution, which evokes feeding activity, i.e. rhythmic opening-closing movements of the mouth (Kemenes et al. 1986). The feeding experiment was made on the 21 st day of treatment. After 10-min acclimatisation, the evoked feeding rate was characterised by a counter for $2 \mathrm{~min}$ (the number of bites/2 $\mathrm{min}$ ).

\section{Statistical analysis}

Statistical analysis was performed using the OriginPro8 2015 software (OriginLab Corp., Northampton, Massachusetts, USA). Normality of the dataset was investigated using the Shapiro-Wilk test, homogeneity of variances between groups 
investigated using Levene's statistic. For the analysis of hatching time, heart rate and feeding activity of embryos, two-way repeated-measure ANOVA was used to assess main effects of time, treatment, and time treatment interaction. This analysis was followed by one-way ANOVA and Scheffe's post hoc test to identify significant differences between control and treatment groups within a given time point. Differences between the control and treated groups of gliding activity of embryos as well as locomotion and feeding activity of adults were analysed using one-way ANOVA with Scheffe's post hoc test. Differences were considered statistically significant at $P<0.05\left(^{*}\right)$ and $P<0.01(* *)$. Error bars in the figures indicate mean \pm standard error.

\section{Results}

\section{Embryos}

There was no observed lethality at any applied progestogen concentrations during the entire 15 days of the study period. The results of the effect of chronic progestogen exposure on the embryonic development of $L$. stagnalis are presented from the 10th embryonic day in Fig. 1. The progestogen exposure in all applied concentration caused a remarkable change in the hatching time of embryos. Two-way repeated-measure ANOVA revealed significant effects of time (observation day) $[F(5,60)=209.49, P<0.0001]$ and treatment $[F(4,60)$ $=20.92, P<0.0001]$, and a significant time $\times$ treatment interaction $[F(20,60)=4.26, P<0.0001]$. No significant difference was detected in the first 3 observation days between the control and treated groups. From the 13th embryonic day, the

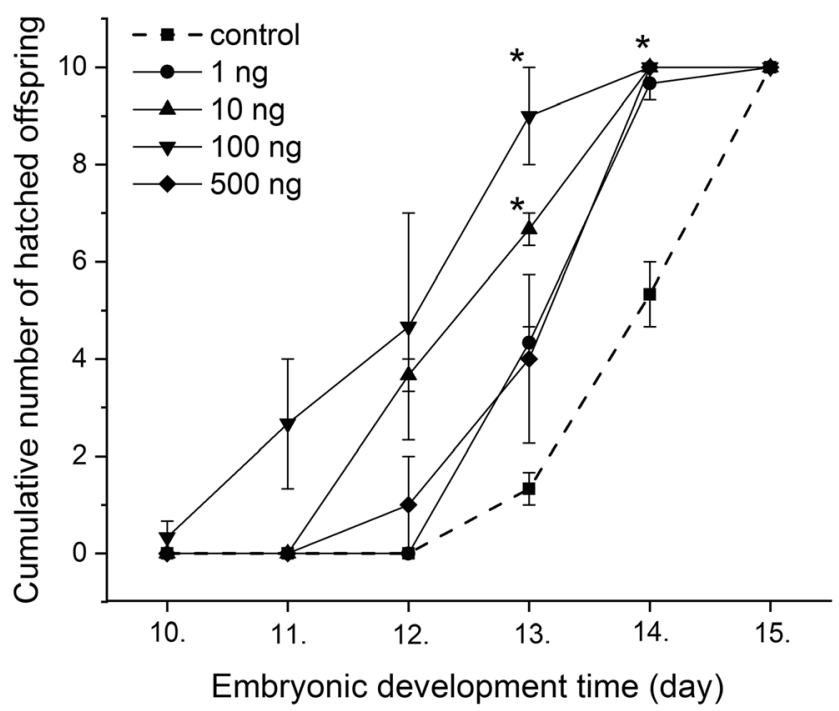

Fig. 1 Embryonic development and hatching rate during the progestogen exposure. Dotted line indicates control. $* P<0.05$, between control and treated groups. Error bars in the figures indicate mean \pm s.e. $n=10$ embryos/group/well/replicates hatching rate significantly increased in the 10 and $100 \mathrm{ng} \mathrm{L}^{-1}$ treated groups. The most of the embryos in the treated groups hatched to the 14th day $(9 / 10,10 / 10,10 / 10$, and $10 / 10$ in 1 , $10,100,500 \mathrm{ng} \mathrm{L}^{-1}$-treated groups, respectively) showing a significant increase comparing to the control (average $5 / 10$ on the 14th day). Alterations of the heart rate, followed from the 6th embryonic day (after the heart developed) for 6 days, are presented in Fig. 2 showing the relative heart rates of treated groups (standardised to original control values) to the control (standardised to themselves, $y=1$ ). Two-way repeated-measure ANOVA revealed significant effects of time (observation day) $[F(5,60)=155.54, P<0.0001]$ and treatment $[F(4,60)=$ $81.02, P<0.0001]$, and a significant time $\times$ treatment interaction $[F(20,60)=11.67, P<0.0001]$. Further analysis with one-way ANOVA and post hoc test indicated that there was no significant difference in the heart rate between the control and $1 \mathrm{ng} \mathrm{L}{ }^{-1}$ progestogen-treated groups in case of all time points (observation days). No significant difference was detected in the first 3 observation days between the control and $10,500 \mathrm{ng} \mathrm{L}^{-1}$ groups; however, the embryos of the $100 \mathrm{ng}$ $\mathrm{L}^{-1}$-treated group started showing significantly higher heart rate on the 2 nd and 3 rd days. On the 4 th -5 th observation days, the heart rate of the embryos of 10,100 , and $500 \mathrm{ng} \mathrm{L}^{-1}$ treated groups significantly increased with a maximum 2.1 -, 2.2-, and 2.4-fold change, respectively. However, during the developmental progress, this exciting effect decreased to 1.5 fold change (still significant). Before hatching, embryonic heartbeat is known to start being similar to the lower postembryonic heartbeat, the shorter duration of embryonic life in the progestogen-exposed groups (see Fig. 1) can explain the lower fold change. Intracapsular locomotor activity

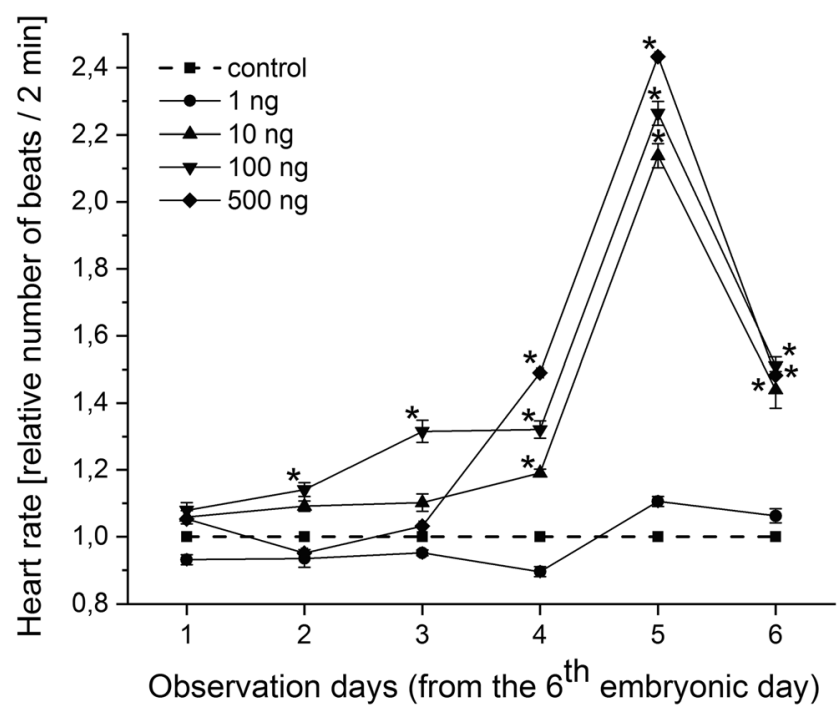

Fig. 2 Relative heart rate of embryos from the 6th embryonic day. Number of heartbeats in the 2-min test period is shown. Interrupted line indicates control. Within a single observation day, $* P<0.05$ between control and treated groups. Error bars in the figures indicate mean \pm s.e. $n$ $=10 \mathrm{embryos} /$ group $/$ well/replicates 
was followed for 3 days while embryos performing an active gliding behavior from E80 to E90 (Fig. 3). During this period, the cumulative number of gliding activities significantly increased in all of the exposed groups. Alterations of the embryonic feeding activity, followed from the 10th embryonic day, are presented in Fig. 4. Two-way repeated-measure ANOVA revealed significant effects of time (embryonic day) $[F(5,60)$ $=18.17, P<0.0001]$ and treatment $[F(4,60)=3.78, P=$ $0.0062]$, but not significant time $\times$ treatment interaction $[F(20,60)=1.03, P=0.4238]$. Further analysis with oneway ANOVA and post hoc test indicated that there was no significant difference between the control and $1 \mathrm{ng} \mathrm{L^{-1 }}$ progestogen-treated groups during the whole observation period. The characteristic shape of the curve of $1 \mathrm{ng} \mathrm{L}^{-1}$ group follows that of control. No significant difference was detected in the first 3 observation days between the control and the 10 , 100 , and $500 \mathrm{ng} \mathrm{L}^{-1}$ groups. From the 13th embryonic day, the radula protrusion significantly increased in the 10,100, and $500 \mathrm{ng} \mathrm{L}^{-1}$ treated groups.

Interesting observation that the investigated behavioural activities including heartbeat (Fig. 2), gliding (Fig. 3), and feeding activity (Fig. 4) consequently increased in the 10, 100 , and $500 \mathrm{ng} \mathrm{L}^{-1}$-treated groups.

\section{Adult snails}

Similar to the embryos, the chronic progestogen treatments caused marked effects in the adult animals. The spontaneous locomotor activity altered remarkably by the various

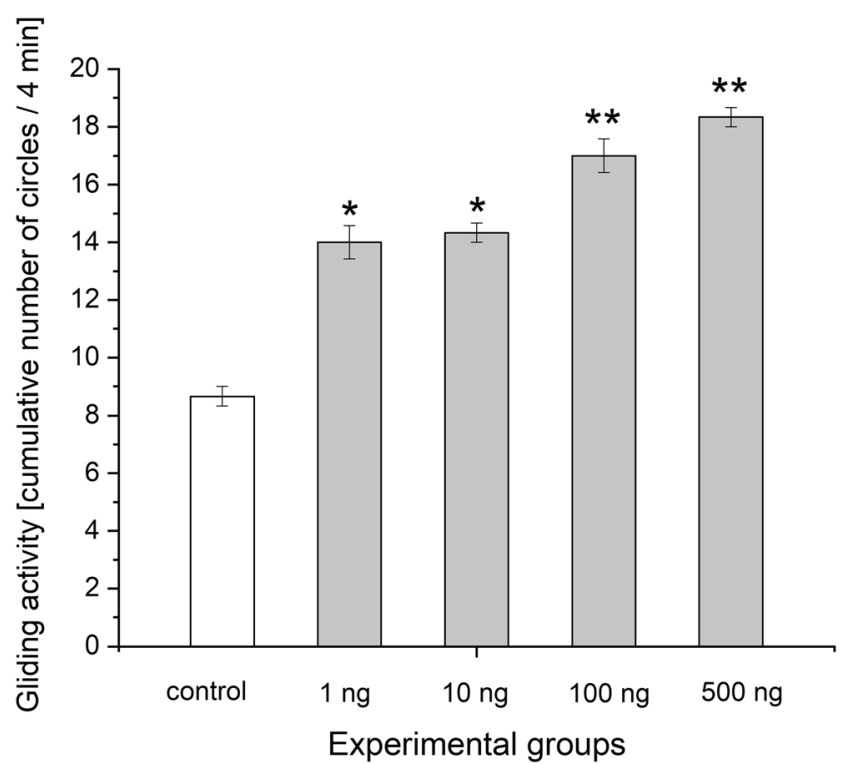

Fig. 3 Gliding activity of embryos in different experimental groups. Cumulative number of circles performed by gliding embryos during 4min time window is shown. The white column represents the control while the greys the treated groups. $* P<0.05$, $* * P<0.01$ between control and progestoge-treated groups. Error bars in the figures indicate mean \pm s.e. $n=10 \mathrm{embryos} /$ group/well/replicates

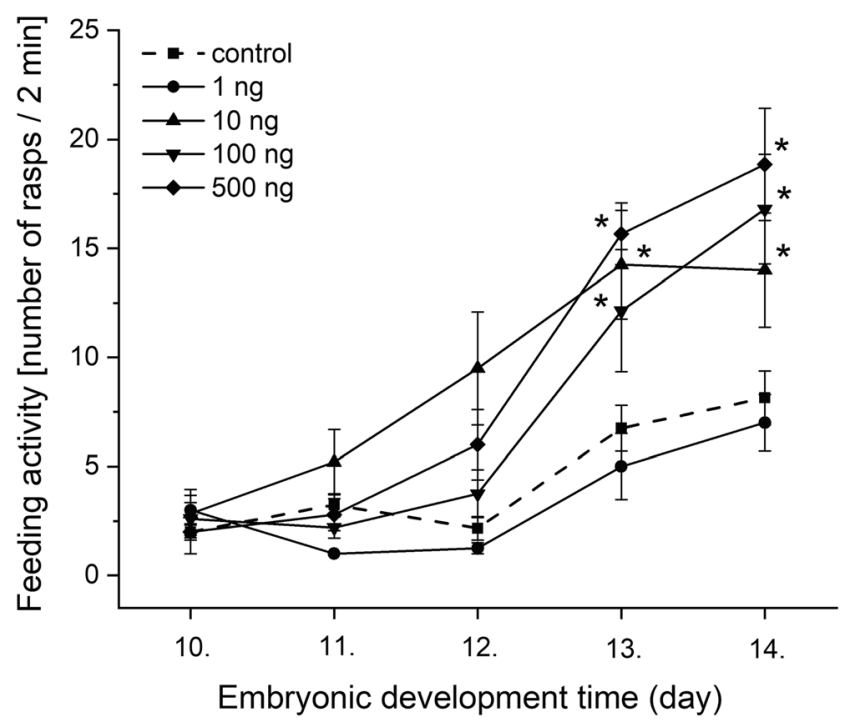

Fig. 4 Feeding activity alterations of embryos observed on the different developmental days. Mean numbers of radula protrusion counted for 2 min are shown. Interrupted line indicates control. Within a single observation day, $* P<0.05$ between control and treated groups. Error bars in the figures indicate mean \pm s.e. $n=10$ embryos/group/well/ replicates

concentration treatments (Fig. 5). Specimens in the 1 and $10 \mathrm{ng} \mathrm{L}^{-1}$ groups covered a shorter average distance $(8.7 \pm$ 0.84 and $7.1 \pm 0.76 \mathrm{~cm}$, respectively) representing a significantly decrease in the locomotion compared with the control group $(15.2 \pm 0.74 \mathrm{~cm})$. However, the locomotion test showed a significant increase in the $100 \mathrm{ng} \mathrm{L}^{-1}$-treated group $(19.1 \pm$ $1.07 \mathrm{~cm}$ ) compared to the control one. In contrast, the $500 \mathrm{ng}$ $\mathrm{L}^{-1}$ group did not show significant difference in locomotion activity $(17.2 \pm 1.01 \mathrm{~cm})$. The results of the exposure on the

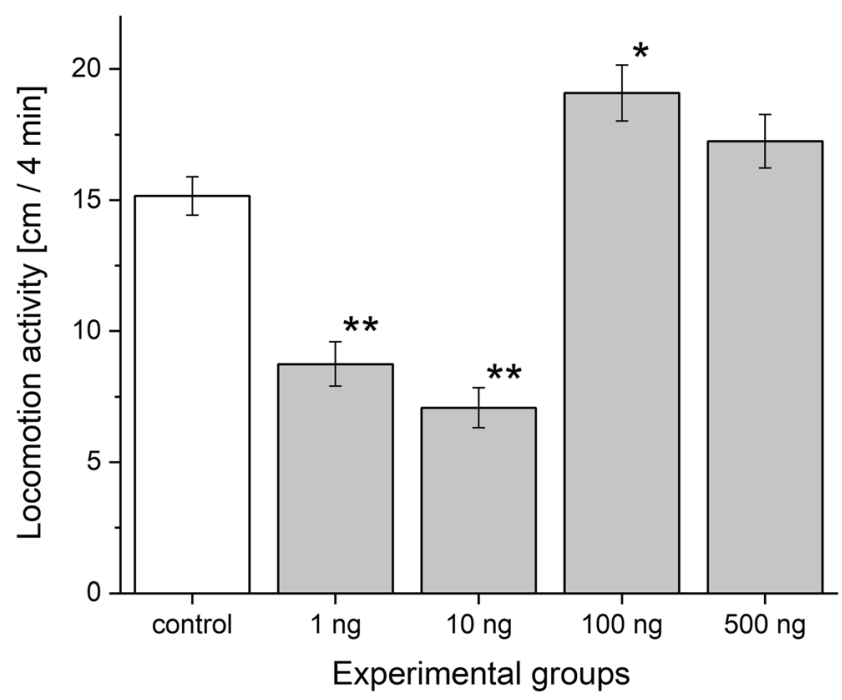

Fig. 5 Locomotor activity in adult snails of experimental groups. Mean distances covered by snails during the 4-min test period are presented. The white column represents the control while the greys the treated groups. $* P<0.05, * * P<0.01$ between control and progestogen-treated groups. Error bars in the figures indicate mean \pm s.e. $n=12$ adults/group/ tank/replicates 


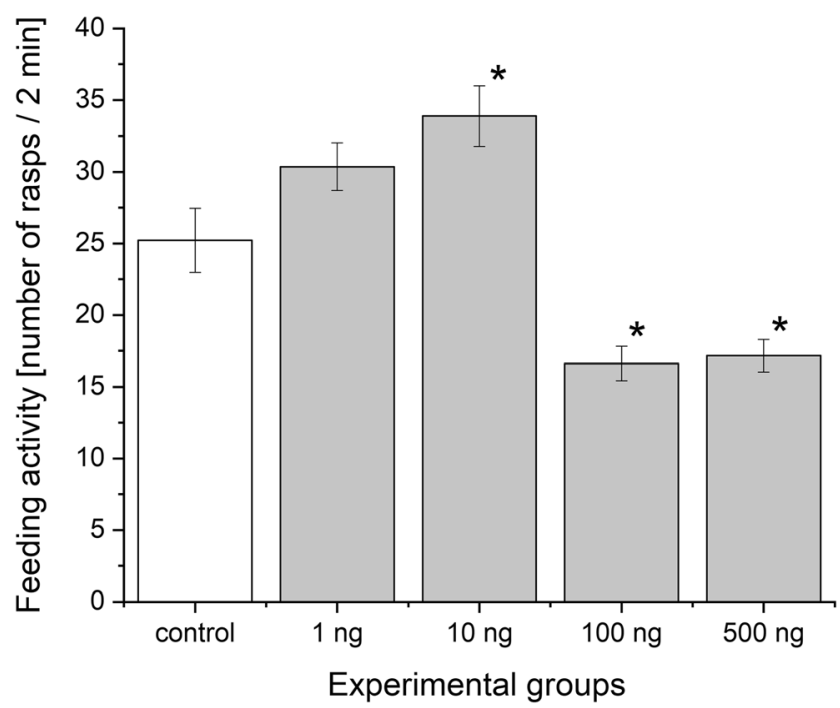

Fig. 6 Feeding activity in adult snails of experimental groups. Mean numbers of rasp counted for $2 \mathrm{~min}$ are shown. The white column represents the control while the greys the treated groups. ${ }^{*} P<0.05$ between control and progestogen-treated groups. Error bars in the figures indicate mean \pm s.e. $n=12$ adults/group/tank/replicates

feeding activity are shown in Fig. 6. Compared to the control (25.2 \pm 2.25 number of bites), the number of rasp slightly increased in the $1 \mathrm{ng} \mathrm{L}^{-1}$ group (30.4 \pm 1.67 number of bites, but this was not significant) and significantly increased in the $10 \mathrm{ng} \mathrm{L}^{-1}$ progestogen-treated animals ( $33.9 \pm 2.10$ number of bites). However, the 100 and $500 \mathrm{ng} \mathrm{L}^{-1}$ groups showed a significantly decreased rate $(16.6 \pm 1.19$ and $17.1 \pm 1.14$ number of bites, respectively) in the feeding activity. According to our findings, the progestogen exposure affected not only the embryos but also the adult specimens. The alterations of these adult behaviours showed a biphasic response; however, they changed approximately in the opposite way.

\section{Discussion}

\section{Environmental relevance of experimental arrangement}

To place our findings in such type of ecotoxicological studies and to evaluate their environmental relevance, we summarised the available international scientific data of PRG, DRO, GES, and LNG identified in different watercourses (Table 1). The concentration ranges of these compounds in $\mathrm{ng} \mathrm{L}^{-1}$ are as follows: $0.06-9330.00,0.20-170.00,0.61-8.3$, and $0.26-$ 4.30 for PRG, DRO, GES, and LNG, respectively. Compared to these, we applied 1, 10, 100, and $500 \mathrm{ng} \mathrm{L}^{-1}$ progestogen concentrations for the exposure of $L$. stagnalis that can be definitely considered as environmentally relevant values. Following the experimental design of our previous study (Zrinyi et al. 2017), in which the results of recovery measurements (applying an HPLC-MS method by Avar et al. 2016) indicated that the actual concentrations were always $\geq 80 \%$ of the nominal concentration in experimental tanks even after 1 week, in the present study, the water and progestogens were renewed only weekly in case of adults. Using progestogens in mixture and in environmentally relevant concentrations, as they are present in the natural habitat (Guzel et al. 2019), for our controlled laboratory investigations, we made an effort to mimic the realistic environmental situation. We think that this approach was met in case of adult specimens but not fully in case of embryos.

Pond snail embryos have been the subject of many studies, but in most cases, toxic effects, such as hatching, were determined for intact egg masses (Gomot 1998; Khangarot and Das 2010; Das and Khangarot 2011). However, as also presented in a previous study which compared the sensitivity of isolated eggs and intact egg masses of pond snail Radix auricularia to cadmium (Liu et al. 2013), the gelatin matrix around eggs of egg masses has evolved to protect them against threats from the environment during their development. Therefore, it limits the sensitivity of snail embryos to some extent. Furthermore, eggs frequently infected by parasites in the field (or even in the laboratory in some cases) can be discarded by the isolation procedure. Hence, the isolated eggs seem better suitable for toxic assays and risk assessment since they lower the individual differences between developing eggs. Moreover, similar to previous studies (Marois and Croll 1991; Voronezhskaya et al. 1999; Filla et al. 2009), usage of isolated eggs embryos has even a technical reason: ensuring much greater synchrony in hatching, the appropriate tracking of behaviours, and more standardised and reproducible experiments.

\section{Progestogens-induced alterations in L. stagnalis}

In our previous study, we presented that parental progestogen exposure caused alterations in the intracapsular development and metabolomics composition in the examined early phase of embryonic development of L. stagnalis (Zrinyi et al. 2017). In the present study, we extended this previous investigation, exposed the embryos and followed the alterations during the whole embryonic development to get more information about the mode of action of different progestogen concentrations $(1,10,100$, and $500 \mathrm{ng} \mathrm{L}^{-1}$ ). The parental exposure did not influence the hatching time of embryos (Zrinyi et al. 2017); however, the direct exposure of isolated eggs in the 10, 100, $500 \mathrm{ng} \mathrm{L}^{-1}$-treated groups resulted in a quicker hatching rate (Fig. 1). External environmental stimuli including active drug residues are known to influence the embryonic development. One such potential pathway could be the energy budget of the developing embryos; our previous results, as there is a significantly elevated hexose utilisation in the embryos and elevated adenylate energy 
Table 1 Measured environmental concentration (MEC) and summarized concentration range (italic values) of different progestogen residues in water samples. $P R G$ progesterone, $L N G$ levonorgestrel, GES gestodene, DRO drospirenone, HPLC-MS/MS high-performance liquid chromatography-tandem mass spectrometry, UHPLC-MS/MS ultra-high

\begin{tabular}{|c|c|c|c|c|}
\hline Progestogens & Watercourse name & MEC ng L ${ }^{-1}$ & Analytical methods & References \\
\hline \multirow[t]{39}{*}{ PRG } & Catchment area of Lake Balaton, Hungary & $0.23-13.67$ & HPLC-MS/MS & Avar et al. 2016 \\
\hline & Catchment area of Lake Balaton, Hungary & $0.60-2.30$ & SFC-MS/MS & Maasz et al. 2019 \\
\hline & Surface water, Rio de Janeiro, Brazil & $0.51-47.20$ & LC-MS/MS & Kuster et al. 2009 \\
\hline & River Lee, Ireland & 6.00 & GC-MS & Aherne et al. 1984 \\
\hline & Paper mill effluent, Fenholloway River, USA & $<10.00$ & HPLC-MS/MS & Jenkins et al. 2003 \\
\hline & Urban Rivers, Bejing, China & 26.00 & LC-MS/MS & Chang et al. 2009 \\
\hline & Snowmelt runoff, Wisconsin, USA & 375.00 & HPLC-MS/MS & DeQuattro et al. 2012 \\
\hline & Grazing Rangeland surface water, California, USA & 27.00 & GC-MS/MS & Kolodziej and Sedlak 2007 \\
\hline & Surface water of agricultural, Pennsylvania, USA & $7.35-11.81$ & GC-MS & Velicu and Suri 2009 \\
\hline & River Llobregat and drinking water, Barcelona, Spain & $\leq 1.39$ & LC-MS/MS & Kuster et al. 2008 \\
\hline & Surface and ground water, French & $1.70-4.10$ & LC-MS/MS (ESI) & Vulliet et al. 2008 \\
\hline & Surface and drinking water, Japan & $0.06-0.09$ & LC-MS/MS & Chang et al. 2008 \\
\hline & Surface and drinking water, Conghua, China & $1.20-2.50$ & UHPLC-MS/MS) & Liu et al. 2014 \\
\hline & Surface and drinking water, Baden, Switzerland & $4.00-10.00$ & LC-MS/MS & Ammann et al. 2014 \\
\hline & River Danshui upstream Guandong, China & $0.50 \pm 0.10$ & RRLC-MS/MS & Liu et al. $2011 b$ \\
\hline & River Danshui downstream, Guandong, China & $2.50 \pm 0.10$ & RRLC-MS/MS & Liu et al. $2011 \mathrm{~b}$ \\
\hline & River Piracicaba, Brazil & 0.58 & LC-ESI-MS/MS & Torres et al. 2015 \\
\hline & Surface water, USA & 0.199 & GC-MS & Kolpin et al. 2002 \\
\hline & Domestic WWTP effluent, Belgium & $2.50 \pm 0.70$ & GC-MS/MS & Pauwels et al. 2008 \\
\hline & WWTP effluent, Japan & $0.31-0.37$ & LC-MS/MS & Chang et al. 2008 \\
\hline & WWTP effluent, Bohai, China & $0.80-2.30$ & RRLC-MS/MS & Liu et al. 2012 \\
\hline & WWTP effluent & 2.90 & LC-MS/MS & Yost et al. 2014 \\
\hline & WWTP effluent, Beijing, China & 6.00 & UPLC-MS/MS & Fan et al. 2011 \\
\hline & Domestic WWTP influent, Belgium & $4.80-33.00$ & GC-MS/MS & Pauwels et al. 2008 \\
\hline & WWTP influent, Japan & $3.10-10.00$ & LC-MS/MS & Chang et al. 2008 \\
\hline & WWTP influent, Bejing, China & $66.00 \pm 36.00$ & LC-MS/MS & Chang et al. 2011 \\
\hline & WWTP influent, Huiyang, Guangdong, China & $6.10 \pm 0.30$ & RRLC-MS/MS & Liu et al. $2011 b$ \\
\hline & WWTP influent, Meihu, Guangdong, China & $5.40 \pm 0.60$ & RRLC-MS/MS & Liu et al. $2011 \mathrm{~b}$ \\
\hline & WWTP influent, Bohai, China & $38.00-108.00$ & RRLC-MS/MS & Liu et al. 2012 \\
\hline & WWTP influent & 10.10 & LC-MS/MS & Yost et al. 2014 \\
\hline & WWTP influent, Beijing, China & 57.00 & UPLC-MS/MS & Fan et al. 2011 \\
\hline & WWTP influent, Baden, Switzerland & 4.15 & LC-MS/MS & Ammann et al. 2014 \\
\hline & Animal farm waste water, Bohai lagoons, China & $56.70-2470.00$ & RRLC-MS/MS & Liu et al. 2012 \\
\hline & Animal farm waste water, lagoons, China & $29.00-11.90$ & RRLC-MS/MS & Liu et al. 2012 \\
\hline & Animal farm waste water, lagoons, Jiangmen, China & 5024.00 & UHPLC-MS/MS & Liu et al. 2014 \\
\hline & Animal farm waste water, lagoons & $186.00-1430.00$ & LC-MS/MS & Yost et al. 2014 \\
\hline & Animal farm waste water, lagoons, Colorado, Denver & $<7.00-98.90$ & GC-MS/MS & Yang et al. 2012 \\
\hline & Animal farm (A) waste water, lagoons, China & $1.70-9330.00$ & UHPLC-MS/MS & Liu et al. 2015 \\
\hline & Animal farm (B) waste water, lagoons, China & $2.31-5402.00$ & UHPLC-MS/MS & Liu et al. 2015 \\
\hline \multicolumn{2}{|c|}{ Concentration range of PRG: } & $0.06-9330.00$ & & \\
\hline \multirow[t]{2}{*}{ LNG } & Catchment area of Lake Balaton, Hungary & $0.85-3.40$ & HPLC-MS/MS & Avar et al. 2016 \\
\hline & Catchment area of Lake Balaton, Hungary & $1.90-49.40$ & SFC-MS/MS & Maasz et al. 2019 \\
\hline
\end{tabular}

performance liquid chromatography-tandem mass spectrometry, $R R L C$ $M S / M S$ rapid resolution liquid chromatography-tandem mass spectrometry, $S F C-M S / M S$ supercritical fluid chromatography-tandem mass spectrometry, GC-MS gas chromatography-mass spectrometry, ELISA enzyme-linked immunosorbent assay 
Table 1 (continued)

\begin{tabular}{|c|c|c|c|c|}
\hline Progestogens & Watercourse name & MEC ng L ${ }^{-1}$ & Analytical methods & References \\
\hline & Surface and ground water, French & $5.30-11.00$ & LC-MS/MS & Vulliet et al. 2008 \\
\hline & Mean surface waters, Rhône-Alpes region, French & 3.60 & LC-MS/MS & Vulliet and Cren-Olivé 2011 \\
\hline & River water, Malaysia & 38.00 & LC-MS/MS & Al-Odaini et al. 2010 \\
\hline & Rivers Anoia and Cardener, Catalonia, Spain & $<0.20-4.00$ & LC-MS & Petrovic et al. 2002 \\
\hline & WWTP effluent, Catalonia, Spain & $<0.20-4.00$ & LC-DAD-MS & Lopez de Alda et al. 2002 \\
\hline & WWTP effluent, River Seine, French & $<2.50-7.20$ & GC-MS & Labadie and Budzinski 2005 \\
\hline & WWTP effluent, River Jalle d'Eysines, French & $<2.00-5.00$ & GC-MS & Labadie and Budzinski 2005 \\
\hline & WWTP effluent, area of Lyon, French & $0.90-17.90$ & LC-MS & Vulliet et al. 2007 \\
\hline & WWTP effluent, China & 1.10 & HPLC & Pu et al. 2008 \\
\hline & WWTP effluent, China & 1.30 & ELISA & Pu et al. 2008 \\
\hline & WWTP effluent, Montreal,Canada & 30.00 & LC-MS/MS & Viglino et al. 2008 \\
\hline & WWTP effluent, River Funan Chengdu, China & 8.10 & HPLC & Qiao et al. 2009 \\
\hline & WWTP influent, River Funan Chengdu, China & 74.30 & HPLC & Qiao et al. 2009 \\
\hline & WWTP influent, Montreal,Canada & $150.00-170.00$ & LC-MS/MS & Viglino et al. 2008 \\
\hline & WWTP influent, China & 6.50 & ELISA & Pu et al. 2008 \\
\hline & WWTP influent, China & 5.60 & HPLC & Pu et al. 2008 \\
\hline & WWTP influent, Spain & $<0.20-16.10$ & LC-MS & Petrovic et al. 2002 \\
\hline & WWTP influent, Catalonia, Spain & $<0.20-16.00$ & LC-DAD-MS & Lopez de Alda et al. 2002 \\
\hline & WWTP influent, Bejing, China & $4.90 \pm 1.20$ & LC-MS/MS & Chang et al. 2011 \\
\hline \multicolumn{2}{|c|}{ Concentration range of $\mathrm{LNG}$} & $0.20-170.00$ & & \\
\hline \multirow[t]{2}{*}{ GES } & River Danube, Hungary & 3.60 & LC-MS/MS & Neale et al. 2015 \\
\hline & WWTP effluent, Beijing, China & $0.61-8.30$ & UHPLC-MS/MS & Shen et al. 2018 \\
\hline \multicolumn{2}{|c|}{ Concentration range of GES } & $0.61-8.30$ & & \\
\hline DRO & Catchment area of Lake Balaton, Hungary & $0.26-4.30$ & HPLC-MS/MS & Avar et al. 2016 \\
\hline
\end{tabular}

charge in the egg albumen (Zrinyi et al. 2017), support this theory. It is possible (though speculative) that the elevated energy utilisation induced by progestogens is present during the whole embryonic development which could explain the observed acceleration of the embryonal behaviour activities (heartbeat, gliding, and radula protrusion). However, to determine the exact underlying mechanisms, further investigations are required with energybased approaches such as dynamic energy budget theory (Zonneveld and Kooijman 1989; Kooijman 2000; Ducrot et al. 2010). In case of the hatching rate of embryos as well as the feeding activity of adult specimens, the doseresponse phenomenon can be identified as a hormesis response (Calabrese and Baldwin 2003). The opposite change of feeding and locomotor activity of adult specimens can be explained with previous results as the activation of some kind of motor activity simultaneously suppresses ongoing feeding ingestion behaviour, even in the presence of food (Pirger et al. 2014). Furthermore, it was discovered that the locomotor and feeding autonomous circuits underlying the execution of these two opposing behaviours are connected via a single type of interneuron, the pleurobuccal (P1B) cell, functioning as a switch (Pirger et al. 2020).

In general, there is a diverse literature on the reproductive and developmental effects as well as the induced behavioural responses of potential endocrine disruptive PhACs including progestogens in invertebrates. Furthermore, there is a longstanding debate about whether, or not, natural vertebrate and synthetic sex steroid residues occurring in the environment can affect the neuroendocrine system and physiological processes of molluscan species (Alzieu 2000; Amorim et al. 2019; Fodor et al. 2020b; Matthiessen and Gibbs 1998; Scott 2012, 2013, 2018; Tran et al. 2019). Previous studies demonstrated that three key steps-cholesterol side-chain cleavage, 17-hydroxylation, and aromatisation —of the classical vertebrate steroid biosynthetic pathway are either absent, or occur very weakly, in molluscs (reviewed in Fodor et al. 2020b; Scott 2012). Most importantly, the homologues of the enzymes that catalyse the first and third of these reactions in 
vertebrates, as well as the functional sex steroid receptors, have so far not been found in molluscan genomes (Fodor et al. 2020b). Yet, several papers presented that molluscs do seem affected by sex steroids occurring in the surface waters, though most of the bioassay information has been contradicted (reviewed in Scott 2013). Focusing on progestogens, progesterone was shown to affect gametogenesis in the snail Helix pomatia (Csaba and Bierbauer 1979) and in the scallop Mizuopecten yessoensis (Varaksina et al. 1992), to induce vitellogenesis, oocyte proliferation, and spermatozoa activation in the octopus Octopus vulgaris (Di Cristo et al. 2008; Tosti et al. 2001), as well as to induce in vitro gamete release in the scallop Placoplecten magellanicus (Wang and Croll 2003). Besides, though not a progestogen, another endocrine disruptors such as the antiandrogenic (fungicide) vinclozolin was shown to affect some reproductive parameters of $L$. stagnalis after 21-day long exposure in $\mu \mathrm{g} \mathrm{L}^{-1}$ concentrations (Giusti et al. 2014). Based on all of these data, though most likely via non-specific interactions (e.g. with receptors for other compounds) (Fodor et al. 2020b; Scott 2012), the embryos and adult specimens of $L$. stagnalis seem to be sensitive to progestogen contaminations that occur in their natural habitat, but the exact mode of action underlying the ecotoxic effects of these synthetic PhACs remains to be determined. In order to reveal the possible underlying cellular mechanisms, we investigated the changes of four relevant key molecules in the CNS: DJ-1, cAMP responsive element-binding protein (CREB), p38alpha, and c-Jun N-terminal kinase 1 (JNK1). These molecules are identified in L. stagnalis (see Supplementary information). DJ-1 was previously determined as a potential biomarker for environmental progestogen exposure in fish (Maasz et al. 2017). CREB is known to be involved also in different sex steroid signal pathways (Lazennec et al. 2001). p38alpha and JNK1 are considered as stress-activated protein kinases that participate in the cellular response to metabolic and other (environmental) stress conditions such as hormones (Bengal et al. 2020). Furthermore, p38 expression was previously shown to increase in the vertebrate CNS after progestogen treatment (Blackshear et al. 2017). We have found that these molecules show significant quantitative changes during the progestogen exposure (Supplementary Fig. 3). Besides, we would like to highlight that this study does not focus on what the molecular background may be. We just readily accept that progestogens are present in the natural habitat of $L$. stagnalis and investigated whether their presence can cause any detectable changes in the different embryonic and adult behaviours.

\section{Conclusions}

The concentrations of progestogens in the environment vary widely, from a few $n g \mathrm{~L}^{-1}$ to a few hundred $\mathrm{ng} \mathrm{L}^{-1}$ in average. Based on our findings, these progestogens, which occur also in the natural habitat of $L$. stagnalis, can affect the embryos and adult specimens even at average environmental concertation $\left(\sim 10 \mathrm{ng} \mathrm{L}^{-1}\right)$. We observed several induced alterations in the different behaviours such as in the embryonic development time, heart rate, feeding, and gliding activities of embryos as well as in the feeding and locomotion activity of adult specimens. These nonreproductive effects of progestogens were not reported previously on molluscan species. The ecological relevance of our findings was adequate in case of adults but this was moderate in embryos due to applied experimental approach. Our results are consistent with previous data as embryos and adult specimens of $L$. stagnalis are sensitive to human $\mathrm{PhAC}$ residues including progestogens, even at low concentration. However, without identified functional steroid receptors, the molecular mechanisms underlying the physiological and behavioural effects are unknown at present. Although we investigated the potential role of four key molecules, the exact mode of action needs to be determined for understanding these drugs' effects on snails including L. stagnalis.

Supplementary Information The online version contains supplementary material available at https://doi.org/10.1007/s11356-020-12094-z.

Acknowledgements We thank Dr. G. Varbiro (Department of Tisza Research, Danube Research Institute, Centre for Ecological Research, 4026 Debrecen, Hungary) for his kind help in statistical calculations. Also, we appreciate the help of Dr. Z. Zrinyi (Department of Experimental Zoology, Balaton Limnological Institute, Centre for Ecological Research, 8237 Tihany, Hungary) and Dr. K. Kovacs (Department of Biochemistry and Medical Chemistry, Medical School, University of Pécs) in the quantitative molecular analysis. Open access funding provided by ELKH Centre for Ecological Research.

Author contributions R.S. and Z.P. conceptualised and designed the experiments. R.S. performed the experiments. R.S., I.F., and Z.P. analysed the data and made figures. R.S., I.F., J.P., and Z.P. wrote the paper. All the authors read and contributed to the submitted version of the manuscript. R.S and Z.P. acquired the funding and were responsible for resources.

Funding Open Access funding provided by ELKH Centre for Ecological Research. This work was supported by National Brain Project (No. 20171.2.1-NKP-2017-00002) and ÚNKP-19-3 New National Excellence Program of the Ministry of Innovation and Technology (No. OI-3120338/2020).

Data Availability All relevant data are within the manuscript and available from the corresponding author upon request.

\section{Compliance with ethical standards}

Conflict of interest The authors declare that they have no conflict of interest.

Ethical approval All procedures on snails were performed according to the protocols approved by the Scientific Committee of Animal 
Experimentation of the Balaton Limnological Institute (VE-I-001/0189010/2013).

\section{Consent to participate All authors were participated in this work}

Consent to publish All authors agree to publish.

Open Access This article is licensed under a Creative Commons Attribution 4.0 International License, which permits use, sharing, adaptation, distribution and reproduction in any medium or format, as long as you give appropriate credit to the original author(s) and the source, provide a link to the Creative Commons licence, and indicate if changes were made. The images or other third party material in this article are included in the article's Creative Commons licence, unless indicated otherwise in a credit line to the material. If material is not included in the article's Creative Commons licence and your intended use is not permitted by statutory regulation or exceeds the permitted use, you will need to obtain permission directly from the copyright holder. To view a copy of this licence, visit http://creativecommons.org/licenses/by/4.0/.

\section{References}

Aherne GW, English J, Marks V (1984) The role of immunoassay in the analysis of in microcontaminants in water samples. Ecotoxicol Environ Saf 9:79-83

Al-Odaini NA, Zakaria MP, Yaziz MI, Surif S (2010) Multi-residue analytical method for human pharmaceuticals and synthetic hormones in river water and sewage effluents by solid-phase extraction and liquid chromatography-tandem mass spectrometry. J Chromatogr A 1217:6791-6806

Alzieu C (2000) Environmental impact of TBT: the French experience. Sci Total Environ 258:99-102

Ammann AA, Macikova P, Groh KJ, Schirmer K, Suter MJF (2014) LCMS/MS determination of potential endocrine disruptors of cortico signalling in rivers and wastewaters. Anal Bioanal Chem 406:76537665

Amorim J, Abreu I, Rodrigues P, Peixoto D, Pinheiro C, Saraiva A, Carvalho AP, Guimaraes L, Oliva-Teles L (2019) Lymnaea stagnalis as a freshwater model invertebrate for ecotoxicological studies. Sci Total Environ 669:11-28

Avar P, Maasz G, Takacs P, Lovas S, Zrinyi Z, Svigruha R, Takatsy A, Toth LG, Pirger Z (2016) HPLC-MS/MS analysis of steroid hormones in environmental water samples. Drug Test Anal 8:123-127. https://doi.org/10.1002/dta.1829

Bengal E, Aviram S, Hayek T (2020) p38 MAPK in glucose metabolism of skeletal muscle: beneficial or harmful. Int J Mol Sci 2020(21): 6480

Bhandari RK, Deem SL, Holliday DK, Jandegian CM, Kassotis CD, Nagel SC, Tillitt DE, Vom Saal FS, Rosenfeld CS (2015) Effects of the environmental estrogenic contaminants bisphenol A and 17alpha-ethinyl estradiol on sexual development and adult behaviors in aquatic wildlife species. Gen Comp Endocrinol 214:195-219

Blackshear KK, Giessner S, Hayden JP, Duncan KA (2017) Exogenous progesterone isneuroprotective following injury to the male zebra finch brain. J Neuro Res 2017:1-11

Calabrese EJ, Baldwin LA (2003) The hormetic dose-response model is more common than the threshold model in toxicology. Toxicol Sci $71: 246-250$

Caldwell DJ, Mastrocco F, Hutchinson TH, Lange R, Heijerick D, Janssen C, Anderson PD, Sumpter JP (2008) Derivation of an aquatic predicted no-effect concentration for the synthetic hormone, 17 alpha-ethinyl estradiol. Environ Sci Technol 42:7046-7054
Can ZS, Firlak M, Kerc A, Evcimen S (2014) Evaluation of different wastewater treatment techniques in three WWTPs in Istanbul for the removal of selected EDCs in liquid phase. Environ Monit Assess 186:525-539

Chang H, Wu SM, Hu JY, Asami M, Kunikane SC (2008) Trace analysis of androgens and progestogens in environmental waters by ultraperformance liquid chromatography electrospray tandem mass spectrometry. J Chromatogr A 1195:44-51

Chang H, Wan Y, Hu J (2009) Determination and source apportion of five classes of steroid hormones in urban rivers. Environ Sci Technol 43:7691-7698

Chang H, Wan Y, Wu S, Fan Z, Hu J (2011) Occurrence of androgens and progestogens in wastewater treatment plants and receiving river waters: comparison to estrogens. Water Res 45:732-740

Costa DD, Neto FF, Costa MD, Morais RN, Garcia JR, Esquivel BM, Ribeiro CA (2010) Vitellogenesis and other physiological responses induced by 17-beta-estradiol in males of freshwater fish Rhamdia quelen. Comp Biochem Physiol C Toxicol Pharmacol 151:248-257

Csaba G, Bierbauer J (1979) Effect of oestrogenic, androgenic and gestagenic hormones on the gametogenesis (oogenesis and spermatogenesis) in the snail Helix pomatia. Acta Biol Med Ger 38: 11458

Das S, Khangarot BS (2011) Bioaccumulation of copper and toxic effects on feeding, growth, fecundity and development of pond snail Lymnaea luteola L. J Hazard Mater 185(1):295-305

DeQuattro ZA, Peissig EJ, Antkiewicz DS, Lundgren EJ, Hedman CJ, Hemming JD, Barry TP (2012) Effects of progesterone on reproduction and embryonic development in the fathead minnow (Pimephales promelas). Environ Toxicol Chem 31:851-856

Di Cristo C, Paolucci M, Di Cosmo A (2008) Progesterone affects vitellogenesis in Octopus vulgaris. Open Zool L 1:29-36

Ducrot V, Teixeira-Alves M, Lopes C, Delignette-Muller ML, Charles S, Lagadic L (2010) Development of partial life-cycle experiments to assess the effects of endocrine disruptors on the freshwater gastropod Lymnaea stagnalis: a case-study with vinclozolin. Ecotoxicology 19:1312-1321

Ducrot V, Askem C, Azam D, Brettschneider D, Brown R, Charles S, Coke M, Collinet M, Delignette-Muller ML, Forfait-Dubuc C, Holbech H, Hutchinson T, Jach A, Kinnberg KL, Lacoste C, Le Page G, Matthiessen P, Oehlmann J, Rice L, Roberts E, Ruppert K, Davis JE, Veauvy C, Weltje L, Wortham R, Lagadic L (2014) Development and validation of an OECD reproductive toxicity test guideline with the pond snail Lymnaea stagnalis (Mollusca, Gastropoda). Regul Toxicol Pharmacol 70:605-614

Fan Z, Wu S, Chang H, Hu J (2011) Behaviors of glucocorticoids, androgens and progestogens in a municipal sewage treatment plant: comparison to estrogens. Environ Sci Technol 45:2725-2733

Fent K (2015) Progestins as endocrine disrupters in aquatic ecosystems: concentrations, effects and risk assessment. Environ Int 84:115-130

Filla A, Hiripi L, Elekes K (2009) Role of aminergic (serotonin and dopamine) systems in the embryogenesis and different embryonic behaviors of the pond snail, Lymnaea stagnalis. Comp Biochem Physiol C Toxicol Pharmacol 149:73-82

Fodor I, Hussein AA, Benjamin PR, Koene JM, Pirger Z (2020a) The unlimited potential of the great pond snail, Lymnaea stagnalis. Elife 9:e56962. https://doi.org/10.7554/eLife.56962

Fodor I, Urbán P, Scott AP, Pirger Z (2020b) A critical evaluation of some of the recent so-called "evidence" for the involvement of vertebrate-type sex steroids in the reproduction of mollusks. Mol Cell Endocrinol. 516:110949. https://doi.org/10.1016/j.mce.2020. 110949

Frankel TE, Meyer MT, Orlando EF (2016) Aqueous exposure to the progestin, levonorgestrel, alters anal fin development and reproductive behavior in the eastern mosquitofish (Gambusia holbrooki). Gen Comp Endocrinol 234:161-169 
Giusti A, Lagadic L, Barsi A, Thome JP, Joaquim-Justo C, Ducrot V (2014) Investigating apical adverse effects of four endocrine active substances in the freshwater gastropod Lymnaea stagnalis. Sci Total Environ 493:147-155

Gomot A (1998) Toxic effects of cadmium on reproduction, development, and hatching in the freshwater snail Lymnaea stagnalis for water quality monitoring. Ecotoxicol Environ Saf 41(3):288-297

Guzel EY, Cevik F, Daglioglu N (2019) Determination of pharmaceutical active compounds in Ceyhan River, Turkey: Seasonal, spatial variations and environmental risk assessment. Hum Ecol Risk Assess 25:1980-1995. https://doi.org/10.1080/10807039.2018.1479631

Hastie T, Tibshirani R (1986) Generalized Additive Models. Statist Sci 1(3):297-310

Huang B, Sun W, Li X, Liu J, Li Q, Wang R, Pan X (2015) Effects and bioaccumulation of 17beta-estradiol and 17alpha-ethynylestradiol following long-term exposure in crucian carp. Ecotoxicol Environ Saf 112:169-176

Hutchinson TH (2002) Reproductive and developmental effects of endocrine disrupters in invertebrates: in vitro and in vivo approaches. Toxicol Lett 131:75-81

Islam R, Richard MKY, Wayne AO'C, Thi KAT (2020) Parental exposure to the synthetic estrogen 17a-ethinylestradiol (EE2) affects offspring development in the Sydney rock oyster, Saccostrea glomerata. Environ Pollut 266(1):114994

Jenkins RL, Wilson EM, Angus RA, Howell WM, Kirk M (2003) Androstenedione and progesterone in the sediment of a river receiving paper mill effluent. Toxicol Sci 73(1):53-59. https://doi.org/10. $1093 /$ toxsci/kfg042

Kashian DR, Dodson SI (2004) Effects of vertebrate hormones on development and sex determination in Daphnia magna. Environ Toxicol Chem 23:1282-1288

Kemenes G, Elliot CJH, Benjamin PR (1986) Chemical and tactile inputs to the Lymnaea feeding system: effects on behaviour and neural circuitry. J Exp Biol 122:113-137

Ketata I, Denier X, Hamza-Chaffai A, Minier C (2008) Endocrine-related reproductive effects in molluscs. Comp Biochem Physiol C Toxicol Pharmacol 147:261-270

Khangarot BS, Das S (2010) Effects of copper on the egg development and hatching of a freshwater pulmonate snail Lymnaea luteola L. J Hazard Mater 179(1-3):665-675

Kolodziej EP, Sedlak DL (2007) Rangeland grazing as a source of steroid hormones to surface waters. Environ Sci Technol 41:3514-3520

Kolpin DW, Furlong ET, Meyer MT, Thurman EM, Zaugg SD, Barber LB, Buxton HT (2002) Pharmaceutical, hormones, and other organics wastewater contaminants in U.S. streams: a national reconnaissance. Environ Sci Technol 36:1202-1211

Kooijman S (2000) Dynamic energy and mass budgets in biological systems. Cambridge University Press, Cambridge. https://doi.org/ 10.1017/CBO9780511565403

Kuster M, de Alda L'p, Hernando MD, Petrovic M, Martı'n-Alonso J, Barcelo D (2008) Analysis and occurrence of pharmaceuticals, estrogens, progestogens and polar pesticides in sewage treatment plant effluents, river water and drinking water in the Llobregat river basin (Barcelona, Spain). J Hydrol 358:112-123

Kuster M, Azevedo DA, López de Alda MJ, Aquino Neto FR, Barceló D (2009) Analysis of phytoestrogens, progestogens and estrogens in environmental waters from Rio de Janeiro (Brazil). Environ Int 35(7):997-1003. https://doi.org/10.1016/j.envint.2009.04.006

Labadie P, Budzinski H (2005) Determination of steroidal hormone profiles along the Jalle d'Eysines River (near Bordeaux, France). Environ Sci Technol 39:5113-5120

Lazennec G, Thomas JA, Katzenellenbogen BS (2001) Involvement of cyclic AMP response element binding protein (CREB) and estrogen receptor phosphorylation in the synergistic activation of the estrogen receptor by estradiol and protein kinase activators. J Steroid Biochem Mol Biol 77(2001):193-203
Liu ZH, Ogejo JA, Pruden A, Knowlton KF (2011a) Occurrence, fate and removal of synthetic oral contraceptives (SOCs) in the natural environment: a review. Sci Total Environ 409:5149-5161

Liu S, Ying GG, Zhao JL, Chen F, Yang B, Zhou LJ, Lai HJ (2011b) Trace analysis of 28 steroids in surface water, wastewater and sludge samples by rapid resolution liquid chromatography- electrospray ionization tandem mass spectrometry. J Chromatogr A 1218: $1367-1378$

Liu S, Ying GG, Zhou L, Zhang RQ, Chen ZF, Lai HJ (2012) Steroids in a typical swine farm and their release into the environment. Water Res 46:3754-3768

Liu T, Joris MK, Xiaoxiao D, Rongshu F (2013) Sensitivity of isolated eggs of pond snails: a new method for toxicity assays and risk assessment. Environ Monit Assess 185:4183-4190

Liu S, Ying GG, Liu S, Lai HJ, Chen ZF, Pan CG, Zhao JL, Chen J (2014) Analysis of 21 progestagens in various matrices by ultrahigh-performance liquid chromatography tandem mass spectrometry (UHPLC-MS/MS) with diverse sample pretreatment. Anal Bioanal Chem 406:7299-7311

Liu S, Ying GG, Liu YS, Yang YY, He LY, Chen J, Liu WR, Zhao JL (2015) Occurrence and removal of progestagens in two representative swine farms: Effectiveness of lagoon and digester treatment. Water Res 77:146-154

Lopez de Alda MJ, Gil A, Paz E, Barcelo D (2002) Occurrence and analysis of estrogens and progestogens in river sediments by liquid chromatography-electrospray-mass spectrometry. Analyst 127: 1299-1304

Maasz G, Zrinyi Z, Takacs P, Lovas S, Fodor I, Kiss T, Pirger Z (2017) Complex molecular changes induced by chronic progestogens exposure in roach, Rutilus rutilus. Ecotoxicol Environ Saf 139:9-17

Maasz G, Mayer M, Zrinyi Z, Molnar E, Kuzma M, Fodor I, Pirger Z, Takacs P (2019) Spatiotemporal variations of pharmacologically active compounds in surface waters of a summer holiday destination. Sci Total Environ 677:545-555

Marois R, Croll RP (1991) Hatching asynchrony within the egg mass of the pond snail, Lymnaea stagnalis. Invertebrate Reprod Dev 19(2): $139-146$

Matthiessen P, Gibbs PE (1998) Critical appraisal of the evidence for tributyltin-mediated endocrine disruption in mollusks. Environ Toxicol Chem 17:37-43

Matthiessen P, Sumpter JP (1998) Effects of estrogenic substances in the aquatic environment. EXS 86:319-335

Mescheriakov VN (1990) The common pond snail Lymnaea stagnalis. In: DetlafDA, Vassetzky SG (ed) Animal species for developmental studies. Plenum Press, New York, pp 69-132

Morrill JB (1982) Development of the pulmonate gastropod, Lymnaea. In: Harrison W, Cowden RR (eds) Developmental biology of the freshwater invertebrates. Alan R. Liss., New York, pp 399-483

Neale PA, Ait-Aissa S, Brack W, Creusot N, Denison MS, Deutschmann B, Hilscherová K, Hollert H, Krauss M, Novák J, Schulze T, Seiler TB, Serra H, Shao Y, Escher BI (2015) Linking in vitro effects and detected organic micropollutants in surface Water Using MixtureToxicity Modeling. Environ Sci Technol 49(24):14614-14624

OECD (2016) Test No. 243: Lymnaea stagnalis Reproduction Test (OECD Publishing)

Orlando EF, Ellestad LE (2014) Sources, concentrations, and exposure effects of environmental gestagens on fish and other aquatic wildlife, with an emphasis on reproduction. Gen Comp Endocrinol 203: 241-249. https://doi.org/10.1016/j.ygcen.2014.03.038

Pauwels B, Noppe H, De Brabander H, Verstraete W (2008) Comparison of steroid hormone concentrations in domestic and hospital wastewater treatment plants. J Environ Eng ASCE 134(11):933-936

Petrovic M, Sole M, Lopez de Alda MJ, Barcelo D (2002) Endocrine disruptors in sewage treatment plants, receiving river waters, and sediments: integration of chemical analysis and biological effects on feral carp. Environ Toxicol Chem 21:2146-2156 
Pirger Z, Crossley M, Laszlo Z, Naskar S, Kemenes G, O'Shea M, Benjamin PR, Kemenes I (2014) Interneuronal mechanism for Tinbergen's hierarchical model of behavioral choice. Curr Biol 24: 2215

Pirger Z, Zrinyi Z, Maasz G, Molnar E, Kiss T (2018) Pond snail reproduction as model in the environmental risk assessment: reality and doubts. In: Raj S (ed) Biological recources of water. IntechOpen, Croatia, pp 33-53

Pirger Z, László Z, Naskar S, O’Shea M, Benjamin PR, Kemenes G, Kemenes I (2020) Interneuronal mechanisms underlying a learning-induced switch in a sensory response that anticipates changes in behavioural outcomes. bioRxiv. https://www.biorxiv. org/content/10.1101/2020.02.12.944553v2

Postigo C, Lopez de Alda MJ, Barcelo D (2010) Drugs of abuse and their metabolites in the Ebro River basin: occurrence in sewage and surface water, sewage treatment plants removal efficiency, and collective drug usage estimation. Environ Int 36:75-84

Pu C, Wu YF, Yang H, Deng AP (2008) Trace analysis of contraceptive drug levonorgestrel in wastewater samples by a newly developed indirect competitive enzyme-linked immunosorbent assay (ELISA) coupled with solid phase extraction. Anal Chim Acta 628:73-79

Qiao YW, Yang H, Wang B, Song J, Deng AP (2009) Preparation and characterization of an immunoaffinity chromatography column for the selective extraction of trace contraceptive drug levonorgestrel from water samples. Tanlanta 80:98-103

Salanki J, Farkas A, Kamardina T, Rozsa KS (2003) Molluscs in biological monitoring of water quality. Toxicol Lett 140-141:403-410

Scott AP (2012) Do mollusks use vertebrate sex steroids as reproductive hormones? Part I: Critical appraisal of the evidence for the presence, biosynthesis and uptake of steroids. Steroids 77:1450-1468

Scott AP (2013) Do mollusks use vertebrate sex steroids as reproductive hormones? II. Critical review of the evidence that steroids have biological effects. Steroids. 78(2):268-281

Scott AP (2018) Is there any value in measuring vertebrate steroids in invertebrates. Gen Comp Endocrinol 265:77-82

Shen X, Chang H, Sun D, Wang L, Wu F (2018) Trace analysis of 61 natural and synthetic progestins in river water and sewage effluents by ultra-high performance liquid chromatography-tandem mass spectrometry. Water Res 133:142-152

Sitruk-Ware R, Nath A (2010) The use of newer progestins for contraception. Contraception 82:410-417

Tillmann M, Schulte-Oehlmann U, Duft M, Markert B, Oehlmann J (2001) Effects of endocrine disruptors on prosobranch snails (Mollusca: Gastropoda) in the laboratory. Part III: Cyproterone acetate and vinclozolin as antiandrogens. Ecotoxicology 10:373-388

Torres NH, Aguiar MM, Ferreira LF, Americo JH, Machado AM, Cavalcanti EB, Tornisielo VL (2015) Detection of hormones in surface and drinking water in Brazil by LC-ESI-MS/MS and ecotoxicological assessment with Daphnia magna. Environ Monit Assess 187:379

Tosti E, Di Cosmo A, Cuomo A, Di Cristo C, Gragnaniello G (2001) Progesterone induces activation in Octopus vulgaris spermatozoa. Mol Reprod Dev 59:97-105
Tran TKA, Yu RMK, Islam R, Nguyen THT, Bui TLH, Kong RYC, O'Connor WA, Leusch FDL, Andrew-Priestley M, MacFarlane GR (2019) The utility of vitellogenin as a biomarker of estrogenic endocrine disrupting chemicals in molluscs. Environ Pollut 248: $1067-1078$

Varaksina GS, Varaksin AA, Maslennikova LA (1992) Role of sex steroid hormones in spermatogenesis of the scallop Mizuhopecten yessoensis. Biol Morya-Vlad 1-2:77-83

Velicu M, Suri R (2009) Presence of steroid hormones and antibiotics in surface water of agricultural, suburban and mixed-use area. Environ Monit Assess 154:349-359

Viglino L, Aboulfadl K, Prevost M, Sauve S (2008) Analysis of natural and synthetic estrogenic endocrine disruptors in environmental waters using online preconcentration coupled with LC-APPI-MS/MS. Talanta 76:1088-1096

Voronezhskaya EE, Hiripi L, Elekes K, Croll RP (1999) Development of catecholaminergic neurons in the pond snail, Lymnaea stagnalis: I. Embryonic development of dopamine-containing neurons and dopamine-dependent behaviors. J Comp Neurol 404:285-296

Vulliet E, Cren-Olivé C (2011) Screening of pharmaceuticals and hormones at the regional scale, in surface and groundwaters intended to human consumption. Environ Pollut 159:2929-2934

Vulliet E, Baugros JB, Flament-Waton MM, Grenier-Loustalot MF (2007) Analytical methods for the determination of selected steroid sex hormones and corticosteriods in wastewater. Anal Bioanal Chem 387(6):2143-2151. https://doi.org/10.1007/s00216-0061084-z

Vulliet E, Wiest L, Baudot R, Grenier-Loustalot MF (2008) Multi-residue analysis of steroids at sub-ng/L levels in surface and ground-waters using liquid chromatography coupled to tandem mass spectrometry. J Chromatogr A 1210:84-91

Wang C, Croll RP (2003) Effects of sex steroids on in vitro gamete release in the sea scallop, Placoplecte magellanicus. Invertebr Reprod Dev 44:89-100

Yang YY, Gray JL, Furlong ET, Davis JG, ReVello RC, Borch T (2012) Steroid hormone runoff from agricultural test plots applied with municipal biosolids. Environ Sci Technol 46:2746-2754

Yost EE, Meyer MT, Dietze JE, Williams CM, Worley-Davis L, Lee B, Kullman SW (2014) Transport of steroid hormones, phytoestrogens, and estrogenic activity across a swine lagoon/sprayfield system. Environ Sci Technol 48:11600-11609

Zonneveld C, Kooijman S (1989) Application of a Dynamic Energy Budget Model to Lymnaea stagnalis (L.). Funct Ecol 3(3):269-278

Zou E, Fingerman M (1997) Effects of estrogenic xenobiotics on molting of the water flea, Daphnia magna. Ecotoxicol Environ Saf 38:281285

Zrinyi Z, Maasz G, Zhang L, Vertes A, Lovas S, Kiss T, Elekes K, Pirger $Z$ (2017) Effect of progesterone and its synthetic analogs on reproduction and embryonic development of a freshwater invertebrate model. Aquat Toxicol 190:94-103

Publisher's note Springer Nature remains neutral with regard to jurisdictional claims in published maps and institutional affiliations. 